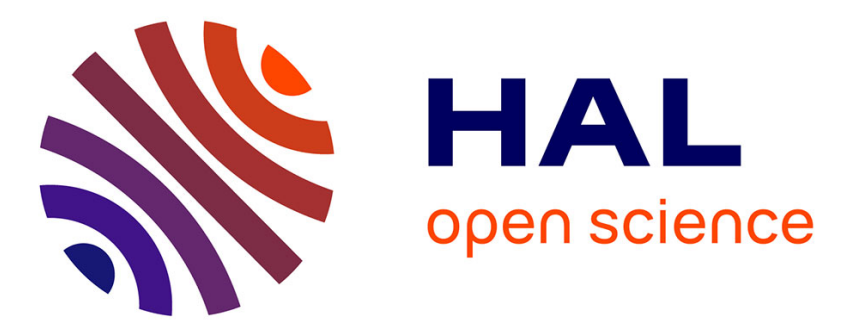

\title{
Application of a probabilistic model for analysing the abortion of seeds and pods in winter oilseed rape (Brassica napus)
}

Xiu Juan Wang, Amélie Mathieu, Paul-Henry P.-H. Cournède, B G Zhang, Philippe de Reffye

\section{To cite this version:}

Xiu Juan Wang, Amélie Mathieu, Paul-Henry P.-H. Cournède, B G Zhang, Philippe de Reffye. Application of a probabilistic model for analysing the abortion of seeds and pods in winter oilseed rape (Brassica napus). Annals of Applied Biology, 2014, 165 (3), pp.414- 428. 10.1111/aab.12152 . hal01510245

\section{HAL Id: hal-01510245 \\ https://hal.science/hal-01510245}

Submitted on 19 Apr 2017

HAL is a multi-disciplinary open access archive for the deposit and dissemination of scientific research documents, whether they are published or not. The documents may come from teaching and research institutions in France or abroad, or from public or private research centers.
L'archive ouverte pluridisciplinaire HAL, est destinée au dépôt et à la diffusion de documents scientifiques de niveau recherche, publiés ou non, émanant des établissements d'enseignement et de recherche français ou étrangers, des laboratoires publics ou privés. 


\title{
Application of a probabilistic model for analysing the abortion of seeds and pods in winter oilseed rape (Brassica napus)
}

\author{
X. J. Wang ${ }^{1,2,5,6}$, A. Mathieu ${ }^{3}$, P.-H. Cournède ${ }^{2}$, P. de Reffye ${ }^{4}$ \& B.G. Zhang ${ }^{1}$ \\ 1 College of Resources and Environmental Sciences, China Agricultural University, Beijing, China \\ 2 Ecole Centrale de Paris, Laboratory MAS 92290, Chatenay-Malabry, France \\ 3 AgroParisTech, UMR 1091 Environnement et Grandes Cultures, Thiverval-Grignon, France \\ 4 CIRAD, AMAP and INRIA, DigiPlante, Montpellier, France \\ 5 The State Key Laboratory of Management and Control for Complex Systems, Institute of Automation, Chinese Academy of Sciences, Beijing, China \\ 6 Dongguan Research Institute of CASIA, Cloud Computing Center, Chinese Academy of Sciences, Dongguan, China
}

\section{Keywords}

Parameter estimation; probabilistic model; seed

and pod abortion; winter oilseed rape.

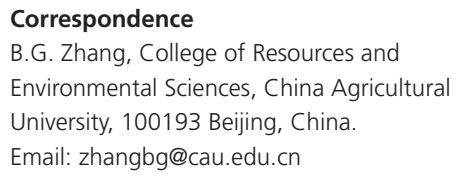

Correspondence

B.G. Zhang, College of Resources and

Environmental Sciences, China Agricultural

University, 100193 Beijing, China.

Email: zhangbg@cau.edu.cn

Received: 17 September 2013; revised version accepted: 4 June 2014.

doi:10.1111/aab.12152

\begin{abstract}
In winter oilseed rape (WOSR), only a subset of ovules can develop into seeds in the majority of pods. Any difficulty during the process of seed production may result in seed or pod abortion. This study aimed to reproduce the process of seed development in WOSR based on a limited number of parameters. As a result of the complexity of the developmental patterns of WOSR, it is challenging to identify the roles of various factors that influence seed production using an experimental approach. Here, we present a stochastic probabilistic model of seed development. The generalised least squares method was implemented to estimate the model parameters using the experimental data. Experiments were done in Grignon (France) in 2008 and 2009. The variations in the parameters were analysed according to the following four factors: year, pod rank, inflorescence position and ramification-clipping treatment. The year had no effect on the number of ovules per ovary $(\mu)$ and the probability of seed viability $(p)$. The proportion of effective pollen grains $(k)$ significantly decreased with pod rank at the end of the main stem. Inflorescence position influenced the number of ovules per ovary ( $\mu$ : 30.8-33.8 from top to bottom) and the parameter $k$. The mean number of seeds per pod on the main stem and the bottom ramification along the stem was larger than the other ramifications within one plant. Ramification-clipping treatment increased the number of ovules per ovary ( $\mu$ : 31 for control plants and 32 for clipped plants), the parameter $k$ and the number of seeds per pod $(p)$. This effect could be due to the competition for assimilates between the pods and seeds. Furthermore, the distribution parameters of the pollen number per stigma $(m)$ remained stable, and the probability of pod survival $(B O)$ varied with different factors, including the year, pod rank and inflorescence position. Our results indicate that pollen germination is a factor that determines final seed number. This model can identify the impact of each of the factors that lead to the abortion of seeds and pods in WOSR, which include the position effect, assimilate competition and pollination limitation. However, further studies on the pollination process in WOSR should help to refine this model.
\end{abstract}

\section{Introduction}

The flower is the reproductive organ of a plant: its function is to ensure the fertilisation of the ovule and the development of fruit containing seeds (Johnstone,
2000). The size and number of reproductive structures show marked variation within inflorescences and plants (Brunet \& Charlesworth, 1995; Diggle, 1995; Obeso, 1993; Stephenson, 1980; Ashman \& Hitchens, 2000). 
In multi-seeded fruits such as apple, pear, grape and kiwifruit, quality criteria including fruit shape, fruit size and the nutrient composition are influenced by the number of seeds (Pyke \& Alspach, 1986; Boselli et al., 1995). The number of seeds per plant is influenced by the number of flowers initiated, the abortion of developing fruits, the number of ovules initiated and the abortion of developing seeds (Lee, 1988). In some plants, a fruit with too few seeds may be aborted (Lee, 1980; Bertin, 1982; Ganeshaiah et al., 1986), resulting in late abortion. Thus, the observed variations in fruit development are due to a number of factors, including the developmental patterns of the floral organs (flower position, flower size, flower number) (Takahata et al., 2008), pollination limitation (Stephenson, 1980; Burd, 1994) and resource availability (Lee, 1988; Stephenson, 1981).

Flower and seed abortion varies with flower position and flowering time due to the developmental patterns of plants (Hiei \& Ohara, 2002). In species showing acropetal inflorescence development, the probability of fruit setting and/or the number of seeds per flower is often lower for distal/late-opening flowers than for proximal/early-opening flowers (Solomon, 1988). Floral variation (in terms of ovule number, floral organ size and fruit size) could account for the pod and seed variation observed within a single inflorescence (Thomson, 1989; Brunet \& Charlesworth, 1995).

The intensity and the efficiency of pollination may also be a critical determinant of the number of seeds (Wertheim, 1991; Brookfield et al., 1996). For example, Burd (1994) reported that $62 \%$ of 258 examined species of angiosperms showed evidence of pollen limitation. The failure of pollen germination and/or the development of pollen tubes that do not penetrate or grow past unfertilised ovules can result in seed abortion (Pechan, 1988). However, when sufficient pollen grains are present, a fertilised ovule cannot form if the ovule is not viable (De Reffye et al., 1978).

When resources are limited, the competition between fruits and the subsequent abortion rate are increased when the number of initiated fruits increases (Udovic \& Aker, 1981; Stephenson, 1980). The rates of seed and pod abortion also increase with defoliation (Stephenson, 1980) and leaf shading (May \& Antcliff, 1963). In addition, flower and seed abortion varies with flower position and the flowering time (Hiei \& Ohara, 2002). One reason for these variations may be that fruits and seeds that develop early receive more assimilates than those that develop later (Stephenson, 1980; Thomson, 1989; Guitian \& Navarro, 1996). Likewise, flowers and seeds located close to the source of assimilates have a greater chance of survival (Nakamura, 1986; Thomson, 1989; Diggle, 1995).
To shed light on the factors influencing reproductive failure, several probabilistic models were developed to simulate the processes of seed production. de Reffye (1974) developed a model of seed formation for tropical crops such as coffee, cacao and oil palm. This model demonstrated that the viability of ovules and embryos is determined genetically in coffee trees, while no significant difference was observed in different trees and plots. Parvais et al. (1977) elaborated a stochastic model of the distribution of the number of pollen grains on each stigma, taking into account the distribution of the number of ovules per flower in cacao trees. These researchers applied the model developed for coffee trees and compared the simulation results to observed data. Based on this model, the variation in pollination rates between seasons was shown to influence cacao yields in the field (Mossu et al., 1981; Falque et al., 1995). As this model relies predominantly on simulation techniques, the estimation of parameter values was empirical. Another example is provided by a model developed to simulate flower pollination and ovule fertilisation in kiwifruit in an orchard setting (Lescourret et al., 1999). This model includes the following four components: the Poisson-distributed deposition of pollen on the stigmas of flowers during the effective pollination period, the selection of fertile pollen grains, the fertilisation of ovules conditioned on the presence of a given number of ovules in the ovary and the selection of fertile ovules.

Brassica napus is a species with a complex reproductive architecture. Yields in this species are determined by four main components: the number of ramifications, the number of pods per ramification, the number of seeds per pod and seed weight (Mendham et al., 1981). Flowering lasts for approximately one month, resulting in a long period of time between the first emergence of pods and the last one. Plants are therefore subject to contrasting environmental conditions, which determine their pollination and trophic state. Diepenbrock (2000) indicated that the ultimate number of pods and seeds produced depends strongly on a continuous supply of assimilates. In winter oilseed rape (WOSR), there is a high rate of seed abortion, and this phenomenon is difficult to analyse due to the complexity of the plant architecture and the temporal patterns observed in this species. Thus, a model could aid in understanding why such a large number of seeds abort.

In this study, we simulated the process of flower fertility in WOSR using a probabilistic model. This model takes into account the following processes related to seed formation: the formation of ovules in the ovary, the effective germination of pollen grains in the stigma, the fertilisation of the ovules, the abortion of fertilised ovules 
and the abortion of pods. Parameters were estimated via the generalised least squares method (GLSQR), fitting the model to experimental data. We aimed to determine whether the abortion of seeds and pods is affected by pollination and/or resource availability in flowers at different positions according to variations in the parameters between years, flower positions and ramification-clipping conditions.

\section{Materials and methods}

\section{Model description}

Seed production involves several different processes and floral components. First, pollen is produced in the anther and is released when it reaches maturity. Second, a pollen grain germinates when it lands on the stigma of a flower to form a pollen tube, in which two male nuclei are transported into the ovary. Third, a male nucleus fuses with the female gamete at the bottom of the embryo sac to produce a diploid zygote. The other male nucleus fuses with the two polar nuclei in the middle of the embryo sac to produce a triploid endosperm nucleus. This process is known as double fertilisation. Following successful fertilisation, the ovules finally develop into seeds. The zygote grows to become an embryo inside the seed, while the triploid endosperm nucleus divides repeatedly to produce the endosperm. The ovary then enlarges and becomes a fruit. The normal processes of seed formation described above may be interrupted due to fertility problems and result in seed abortion (Arathi et al., 1999).

The model presented here reproduces the major steps from the appearance of flowers to the production of seeds based on probability distributions and focuses on the stages associated with higher probabilities of abortion. The distributions included in the model are as follows:

1. The distribution of the number of ovules in the ovary;

2. The distribution of the number of pollen grains germinating per stigma;

3. The distribution of the number of fertilised ovules;

4. The viability of seeds, meaning the probability that a fertilised ovule will develop into a mature seed;

5. The abortion of a pod according to the number of seeds it contains.

$Y$ is a random variable representing the number of ovules in the ovary and is described as showing a Normal distribution with a mean of $\mu$ and a standard deviation of $\sigma$. In general, a Normal distribution is used to describe any variable that tends to cluster around the mean. Thus, the density function of the number of ovules in an ovary is given by the following Eqn 1:

$$
f_{Y}\left(y ; \mu, \sigma^{2}\right)=\frac{1}{\sigma \sqrt{2 \pi}} \exp \left(-\frac{(y-\mu)^{2}}{2 \sigma^{2}}\right)
$$

According to the assumptions presented by Falque et al. (1995), pollen tubes reach ovules in a similar manner whether the ovules have already been reached by another pollen tube. de Reffye (1974) directly observed the number of pollen grains per stigma in cacao trees with a microscope and found that the Pareto distribution simulated their distribution well. In our study, three probability distribution functions (Pareto, Negative Binomial and Log-Normal) were compared to determine which function best described the distribution of the number of pollen grains per stigma. The Akaike information criterion (AIC) (Akaike, 1973) was used to select the appropriate distribution of the number of pollen grains. The AIC tool for model selection measures the goodness of fit of a model by accounting for the number of parameters in the model and the number of observations. The AIC is computed using Eqn 2:

$$
A I C=2 a+n\left[\ln \left(\frac{2 \pi R s s}{n}\right)+1\right]
$$

where $a$ is the number of parameters in the statistical model, $n$ is the number of observations and Rss is the residual sum of squares between the observed and modelled values.

We found that a Log-Normal distribution (AIC = 6292.3) simulated the number of seeds per pod more accurately than the Pareto distribution $(\mathrm{AIC}=7411.8$ ) and Negative Binomial distribution (AIC $=6347.1$ ). The data set of Experiment 1 was used to compute the AIC values. Thus, we chose a Log-Normal distribution to calculate the number of pollen grains per stigma.

The number of pollen grains that land on a stigma is described by the random variable $T$. The variable $T$ was therefore assumed to follow a Log-Normal distribution, with the following probability density and parameters $m$ and $s$, where $m$ is the mean, and $s^{2}$ is the variance of the distribution of $\ln T$.

$$
f_{T}\left(t ; m, s^{2}\right)=\frac{1}{t s \sqrt{2 \pi}} \exp \left(-\frac{(\ln t-m)^{2}}{2 s^{2}}\right)
$$

A pollen grain is assumed to be effective if it germinates and penetrates into the ovary to pollinate an ovule. The number of effective pollen grains $(X)$ that can germinate and produce pollen tubes on a stigma is described by the random variable $X=k T$, where $k$ represents the ratio of the number of effective to total pollen grains. Therefore, 
the number of effective pollen grains, $X$, is given by the following Eqn 4:

$$
f_{X}\left(x ; k, m, s^{2}\right)=\frac{1}{(x / k) s \sqrt{2 \pi}} \exp \left\{-\frac{[\ln (x / k)-m]^{2}}{2 s^{2}}\right\}
$$

This function also corresponds to a Log-Normal distribution according to the formation of the equation.

As continuous density functions were chosen for the discrete variables (the number of pollen grains and the number of ovules), the discrete form of these continuous distributions can be obtained with the following equation:

$$
P(X=x)=f(x+0.5)-f(x-0.5)
$$

The number of ovules per ovary $X$ and the number of pollen grains per stigma $Y$ are independent, and one effective pollen grain is necessary and sufficient for the fertilisation of one ovule. $Z$ denotes the number of fertilised ovules. We therefore obtain the equation $Z=\min (X, Y)$. The probability of $z$-fertilised ovules is given by the following Eqn 6:

$$
P(Z=z)=P(X=z) P(Y>z)+P(Y=z) P(X \geq z)
$$

The fertilised ovules may develop into mature seeds with a probability of $P$, according to seed viability. This viability is presumably linked to several factors, mainly being associated with assimilate competition. A fertilised ovule is more likely to not form a seed when high assimilate competition occurs. If $S$ is the number of fertilised ovules that form seeds, the probability of obtaining $i$ seeds is given by the following Eqn 7:

$$
\begin{aligned}
P(S=i)= & \sum_{y=0}^{N} C_{i}^{y} p^{i}(1-p)^{y-i} P(Y=y) P(X \geq y) \\
& +\sum_{y=0}^{N} \sum_{k=i}^{y-1} C_{i}^{k} p^{i}(1-p)^{y-i} P(X=k) P(Y=y)
\end{aligned}
$$

where $N$ is the number of ovules per ovary, and

$$
C_{i}^{y}=\frac{y !}{i !(y-i) !} \quad y !=1 \cdot 2 \cdot 3 \cdot \ldots \cdot y
$$

A demonstration of Eqn 7 is provided in Wang et al. (2009).

A pod may abort if it contains too few seeds. In a study examining the frequency distribution of the number of seeds in the pod of Leucaena leucocephala (Lam), Ganeshaiah et al. (1986) found that the formation of pods was related to the number of seeds inside the pods. In the present study, this relationship was modelled with a Beta function, which is a flexible function that is commonly used in biological models (see Yin et al. (2003) for an example). Function $F(i)$ is defined as the cumulative (over seeds per pod) probability of pod survival, which is dependent on the number (i) of seeds per pod as well as parameters $\alpha$ and $\beta$.

$$
\begin{gathered}
F(i)=\sum_{j=1}^{i} \frac{g(i)}{M o} \text { where } \\
g(j)=\frac{1}{N}\left(\frac{j-0.5}{N}\right)^{\alpha-1}\left(1-\frac{j-0.5}{N}\right)^{\beta-1} \text { and } \\
M o=\sum_{j=1}^{N} g(j)
\end{gathered}
$$

This function produces the shape of the distribution of the variation curve of pod survival for the current plant growth condition. In Eqn 9, $N$ is the maximum number of ovules per ovary, which is equal to 50 according to our observations. $F(i)$ is a normalised function that describes the cumulative probability of pod survival during growth.

According to this function, the distribution of pod survival is flexible and can be fitted to experimental data by optimisation. During the general parameterisation of the model parameters via optimisation, only one parameter $(B O)$ is optimised to define the Beta function (Guo et al., 2006), and its two parameters $\alpha$ and $\beta$ are subsequently derived from Bo by iteration using the constraints $\alpha+\beta=$ Co and

$$
\alpha /(\alpha+\beta)=\text { Bo }
$$

Co is equal to an empirical value of 4 . These constraints are empirical and generally yielded better results than the other possible constraints (i.e. other fixed values for Co as $1,2,3,5 \ldots)$, when modelling different data sets of numbers of seeds per pod.

$B$ is a random variable that represents the final number of seeds per pod; assuming that the number of fertilised ovules $S$ and the probability of pod survival $F(i)$ are independent, its probability distribution is given by the following Eqn 11:

$$
P(B=i)=P(S=i) F(i)
$$

By combining these distributions, we can compute the final number of seeds per pod. The model was developed in Scilab 4.0, and the parameters used in the model are listed in the Table 1.

\section{Parameter estimation}

The parameters $\mu$ and $\sigma$ (Table 1) were estimated for a Normal distribution using the maximum likelihood estimation method. Parameter values of the pollen grain $(m, s, k)$, seed viability $(p)$ and pod survival $(B o)$ distributions were estimated using the generalised least squares 
Table 1 Model parameters

\begin{tabular}{lll} 
Parameters & Distributions & Descriptions \\
\hline$\mu$ & Normal & Parameter for the distribution of ovule numbers \\
$\sigma$ & Normal & Parameter for the distribution of ovule numbers \\
$m$ & Log-normal & Parameter for the distribution of pollen numbers \\
$s$ & Log-normal & Parameter for the distribution of pollen numbers \\
$k$ & Log-normal & Parameter for the percentage of effective pollen \\
$p$ & Bernoulli & Parameter for the viability of seeds \\
$\alpha$ & Beta & Parameter for pod survival \\
$\beta$ & Beta & Parameter for pod survival \\
Bo & Beta & Parameter for pod survival \\
\hline
\end{tabular}

$\alpha$ and $\beta$ can be calculated according to constraint formulas $10 . \mu$ and $m$ are means and $\sigma$ and $s$ are standard deviations for the distributions of ovule and pollen numbers; $k$ is the ratio of effective to total pollen grains; $p$ is the probability that an ovule develops into a mature seed; $\alpha$ and $\beta$ are the shape parameters for the distribution of pod survival.

method (GLSQR), which is suitable for non-linear systems and is applied when the variances of the observations are unequal (heteroscedasticity), or when there is a certain degree of correlation between the observations. The GLSQR estimator is unbiased, consistent and asymptotically Normal. Thus, the model can well estimate the number of seeds per pod even if systematic error and bias exist.

The model parameters cannot be simultaneously estimated using GLSQR, so a step-by-step method was applied to process the estimation. First, we fixed one or two parameters to estimate the others, and then the latter were fixed sequentially to estimate the previously fixed ones. Generally, after several iterations, the parameter values tended to be stable.

The model parameters were obtained by fitting the model equations to the measured data (the numbers of ovules, seeds). Inverse modelling refers to the estimation of quantities that are directly or indirectly related to the measured quantity. The mathematical principle of inverse modelling has been described in detail by Cournède et al. (2011). Model computation and model fitting based on experimental data were conducted using Scilab 4.0. To compute the distributions of numbers of ovules per ovary and seeds per pod, all the measured data were pooled to estimate the parameters.

Let vector $Z$ be the target data for fitting, let $Y(\theta)$ be the corresponding model output and let $\theta$ be a vector of the model parameters, including those relating to the probabilities of the number of pollen grains $(m, s)$, seed viability $(p)$ and pod survival $(\alpha, \beta)$, as listed in Table 1 . The weighted least square error (weight $W$ is calculated based on the variance of the data) in the following equation is minimised by searching for the best parameter values:

$$
\Phi(\theta)=[Z-Y(\theta)]^{T} W[Z-Y(\theta)]
$$

The process is repeated until the solution is stabilised (no change in $\Phi(\theta)$ and the estimated parameters to the third decimal place) and an optimal solution is found for parameter values. Advantages of this method are its rapid convergence (ten iterations are often sufficient) and its ability to provide the standard deviation linked to the parameter values, indicating the precision of the solution.

The jackknife resampling method was used to test the stability of the fitted model (Sahinler \& Topuz, 2007). The jackknife estimator of a parameter is found by systematically leaving out each observation from a dataset and calculating the estimate and then finding the average of these calculations. Given a sample of size $N$, by estimating the parameter for each subsample $(N-1)$ omitting the $i$ th observation to obtain an estimate $\hat{\theta}_{i}$, the overall jackknife estimator is found by averaging each of these subsample estimators. The mean of the jackknife estimates is given by:

$$
\overline{\widehat{\theta}}=\frac{1}{N} \sum_{i=1}^{N} \hat{\theta}_{i}
$$

On the basis of our experiments (45 plants for 2008, 18 plants for 2009 and 10 plants for clipping treatment), the parameters were estimated with removing one plant from the whole sample at each time. Therefore, the standard error can be computed for each estimated parameters according to the following equation:

$$
\mathrm{SE}=\left[\frac{N-1}{N} \sum_{i=1}^{N}\left(\hat{\theta}_{i}-\overline{\hat{\theta}}\right)^{2}\right]^{\frac{1}{2}}
$$

\section{Field experiments}

\section{Plant materials}

Winter oilseed rape was grown in the field at the INRA experimental unit in Grignon (Yvelines, France, $48.9^{\circ} \mathrm{N}$, $\left.1.9^{\circ} \mathrm{E}\right)$. The self-compatible Mendel cultivar was used in this study. Experiments were conducted over the growing seasons of 2007-2008 and 2008-2009. Agronomic conditions were similar during the two experimental years. Plots were 20 rows, $0.30 \mathrm{~m}$ apart and $30 \mathrm{~m}$ long, and the plots were kept free of weeds, insects and diseases for the 2 years. The sowing density was 50 plants $\cdot \mathrm{m}^{-2}$. The plants started to flower from early April to late May (Tittinel, 1990) and were harvested at the beginning of July. Measurements were carried out from mid-May to mid-July. Measurements were initiated when all of the flowers had developed into pods to ensure that the number of seeds and ovules could be measured in all of the pods of the plant. The number of ovules was counted as the total number of mature and aborted seeds. Flower/pod positions were recorded as follows: 
the ramification/inflorescence-bearing positions were numbered from Rl to Rn from top to bottom along the main stem, for $n$ ramifications on a given plant, with the main stem being numbered R0 and the highest ramification numbered Rl, and the locations of the flowers and pods within each inflorescence were recorded using increasing rank numbers from the base to the tip of the bearing inflorescence, referred to as pod rank. Thus the location of a pod on the plant was indicated by its rank on the bearing inflorescence, and the position of its bearing inflorescence on the main stem.

\section{Experiments}

\section{Experiment 1}

This experiment was done from 2007 to 2008 and focused on the number of ovules and seeds per pod. The positions of pods on the main stem were evaluated. A total of 45 plants with 2067 pods were randomly collected to provide data to calibrate the model. The numbers of mature seeds and aborted seeds were counted, and the positions of pods were recorded on the main stem.

Using these experimental data, we then analysed the differences in the parameter values according to the pod rank (see section Results). Because the number of pods per plant varied from 50 to 90 , where possible the 1st-80th pods were chosen along the stem, or otherwise all pods were used. Because the length of inflorescences is different between plants, pod ranks were normalised for each inflorescence by dividing by the maximum rank on the inflorescence. The sample sizes for pods were different at each pod rank (location of pod on the bearing inflorescence) due to pod abortion. The maximal number of observed pods for each rank was 45. Moreover, to provide enough samples for parameter estimation, the parameters were estimated every five pod ranks, that is, 16 pod groups could be obtained from the measured data.

\section{Experiment 2}

This experiment was done from 2008 to 2009. A total of 18 plants were randomly collected, and all of the pods on the main stem (791 pods) were counted according to the pod rank. The number of pods per plant varied from 57 to 100. To analyse the position effect between ramifications along the stem, the number of seeds and aborted seeds on the main stem (R0), and ramifications R1, R4, R7, R9 and Rll (as a subset along the main stem) were measured according to their positions in the inflorescences of all 18 plants. Accordingly, we analysed the differences in the parameter values between years (combining information from experiments 1 and 2), pod ranks and inflorescences.

\section{Experiment 3}

This experiment was done from 2008 to 2009. To investigate the effect of assimilate availability on the number of ovules and seeds per pod, a total of 10 plants were randomly selected, and all their ramifications were clipped when they appeared and only the main stem remained for each plant. We analysed the differences in the parameter values between the control (CK) and clipped plants (R-).

\section{Statistical methods}

Given data from experiments (described in the above section), the two-sample $t$-test was used to compare the mean number of seeds per pod for different years (2008 and 2009) and treatments (CK and R-). Analysis of variance (ANOVA) was used to compare the mean number of seeds per pod among the inflorescences R0, R1, R4, R7, R9 and R11. All statistical computations were done using R 2.11.1 (Copyright (C) 2010 the R Foundation for Statistical Computing).

The coefficient of determination $\left(R^{2}\right)$ was used to test the correlation between the observed and estimated values for different factors (year, pod rank, inflorescence position and ramification-clipping treatment). This coefficient can be expressed as:

$$
R^{2}=1-\sum_{i=1}^{N} \frac{\left(X_{i}-Y_{i}\right)^{2}}{\left(X_{i}-\bar{X}\right)^{2}}
$$

where $X_{i}$ and $Y_{i}$ are the observed and fitted values, respectively, $\bar{X}$ is the mean of the observed values and $N$ is the sample size.

\section{Model validation}

Monte-Carlo simulation was used to generate observations $(T=1000)$ from the set of distributions proposed. As described, the distributions of the number of ovules per ovary, the number of pollen grains per stigma, the number of seeds per pod and pod survival can be simulated using a Normal distribution, Log-Normal distribution, Bernoulli process and Beta distribution, respectively. To run the model, Monte-Carlo simulation was used to simulate the process of seed production. By comparing the results of the simulation and the computation in different situations, we could validate the output of the model to provide an assessment of the inverse method and the robustness of the estimated parameters given the fixed values imposed in the simulation. 


\section{Results}

Effect of pod rank on the estimated parameter values

Previous data analysis revealed that the pod rank had a significant influence on the number of seeds per pod on the main stem (Wang et al., 2009). The number of seeds per pod remained constant for the first rank and decreased with an increasing rank. Therefore, the variation in parameter values according to the pod rank could be estimated. Here, we compared the variation in the parameter values on the main stem using the data of experiment 1 from 2008.

As it was difficult to simultaneously estimate all the parameters, we used the step-by-step method to estimate the parameters $m, p$ and $B o$ first to see the variation of the three parameters. The means for parameters $m, p$ and Bo were $3.585 \pm 0.066,0.850 \pm 0.008$ and $0.397 \pm 0.005$ $($ mean $\pm \mathrm{SE})$, and the coefficients of variation (CV) were $7.38 \%, 3.59 \%$ and $5.05 \%$, respectively, when the pod rank was the only varying factor. The mean number of ovules per ovary $(\mu)$ (Fig. 1A) did not vary with the pod rank $(C V=1.37 \%)$. The mean of $\mu$ was $31.09 \pm 0.107$ for all pod ranks on the main stem. On the basis of the estimation above, the variation of the parameters $m$ and $p$ were not large, so we fixed $m$ and $p$ to the means of 3.585 and 0.85 to simultaneously estimate the parameters $s, k$ and Bo. The new CVs for $s, k$ and Bo were $37.7 \%, 22.9 \%$ and $11.5 \%$, respectively. The values of each estimated parameter along the pod rank are shown in Fig. 1B. The parameter $s$ varied with the pod rank, although no specific tendency was observed. The percentage of the number of effective pollen grains out of total first increased and then decreased with the pod rank. The probability of pod survival $(B o)$ did not vary with the pod rank when estimating with the parameters $s$ and $k$.

\section{Differences in the estimated parameter values between experimental years}

The model parameters were estimated using the data collected from the two experimental years corresponding to the growing seasons of 2007-2008 (Experiment 1, 45 plants) and 2008-2009 (Experiment 2, 18 plants). The differences between the two years were analysed. First, the parameter $m$ was fixed to 3.585 (the mean estimated from pod ranks) to estimate the other parameters, and then the estimated values were sequentially used to estimate the parameter $m$. Fig. 2 shows the distributions of the number of ovules (Fig. 2A) and seeds per pod (Fig. 2B). The mean number of ovules per pod $(\mu)$ did not vary between years, although the standard deviation $(\sigma)$ was larger in 2008 (Table 2). The mean number of seeds per pod was greater in $2009(24.1 \pm 0.24)$

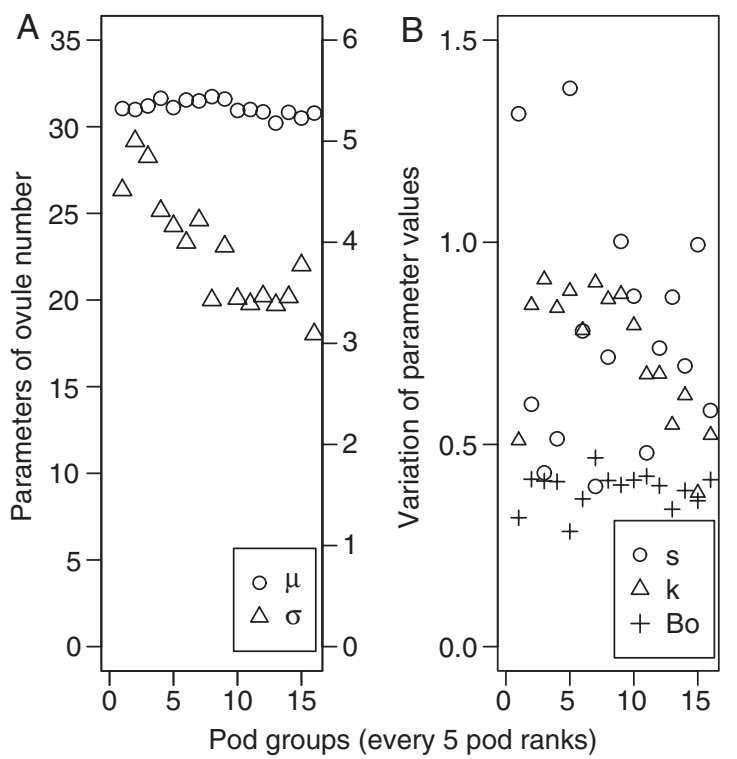

Figure 1 Variation in parameter values with the pod group (every 5 pod ranks). (A) Estimated values for the distribution of number of ovules per ovary $(\mu, \sigma)$ and $(\mathrm{B})$ number of pollen grains per stigma (s), percentage of effective pollen grains $(k)$ and probability of pod survival $(B O)$ according to an increasing pod rank from the bottom to the top of the stem (cv. Mendel).

compared with $2008(22.9 \pm 0.15)$ (two-sample $t$-test, $t=-4.24, \mathrm{~d} f=2856, \mathrm{SED}=0.283, P<0.001)$. The residuals between the observed and fitted number of seeds per pod had larger and larger scatter as the seed number per pod increased. Because all the measured data were combined to estimate the parameters, this could lead to a discrepancy between the estimated and observed number of seeds per pod by ignoring the effect of pod location (the number of seeds per pod first remained constant and then decreased along the main stem (Wang et al., 2011)).

The cumulative probability of the number of pollen grains per stigma being less than 50 was smaller in 2009 (0.674) than in 2008 (0.81) (Fig. 2C). The percentage of effective pollen grains $(k)$ was greater in $2009(k=0.913)$ than in 2008 ( $k=0.88)$ (Table 2).

The probability of seed viability $(p)$ was slightly higher in 2009. Furthermore, the probability of pod survival differed between the two years (Fig. 2D). For a given number of seeds per pod, the probability of pod survival was higher in 2008 than in 2009. This could have been due to the overall growth conditions of the plants.

\section{Effect of inflorescence position on the estimated parameter values}

To analyse the differences in parameter values between inflorescences, the parameter values were estimated for inflorescences R0, R1, R4, R7, R9 and R11 

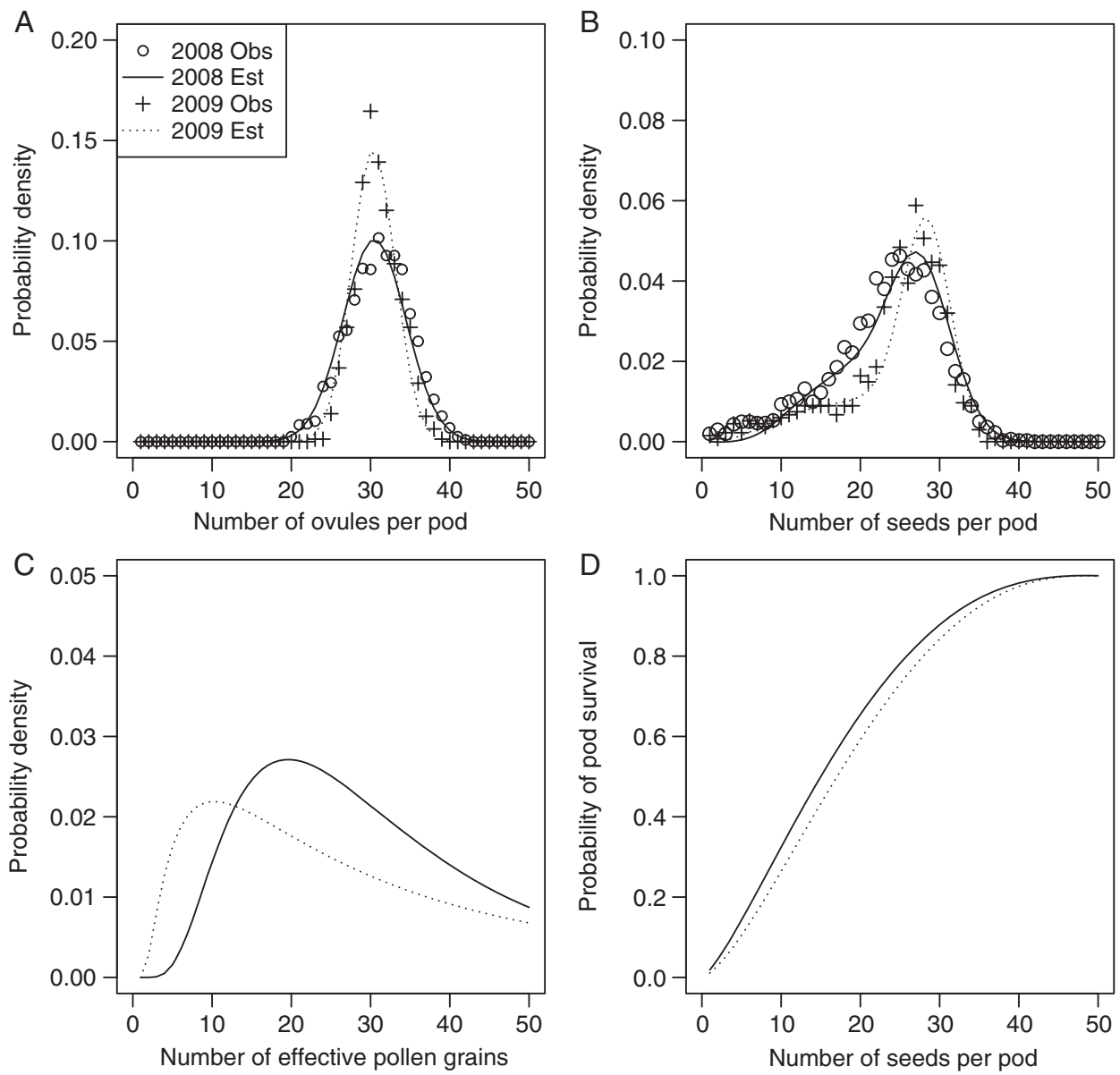

Figure 2 Estimated distributions for each process. (A) Number of ovules per flower, (B) number of seeds per pod, (C) number of pollen grains per flower and (D) probability of pod survival according to the number of seeds per pod on the main stem in 2008 and 2009 (cv. Mendel). The symbols (Obs) and lines (Est) represent the observed and estimated values, respectively.

(Experiment 2). As shown in Fig. 3, the observed number of ovules and seeds could be calibrated for each ramification. Fig. 4 gives the distribution of effective number of pollen grains (A) and the probability of pod survival (B).

On the basis of the estimation of pod ranks, the parameters $m$ did not vary much, so we tried fixing $m$ to 3.5 (the estimated value in 2009, see Table 2) to estimate the other parameters, and then the estimated values were sequentially used to estimate the parameter $m$, as shown in the Table 3. The average number of ovules per pod $(\mu)$ increased slightly with the position of inflorescences from the top to the bottom of the plant. The probability of seed viability $(p)$ did not vary much with the position of the inflorescence (from 0.835 to $0.906, \mathrm{CV}=2.64$ ). The distribution of pollen grain numbers $(s)$ varied but no specific tendency was observed. The proportions of effective pollen grains per flower $(k)$ and the parameter of pod survival (Bo) were lower for ramifications R4, R7 and R9 compared with ramifications $\mathrm{R} 0, \mathrm{R} 1$ and $\mathrm{R} 1 \mathrm{l}$. This result was consistent with the measured data. There were significant differences between these inflorescences (ANOVA, residual $\mathrm{d} f=2232, F=12.3, P<0.001$ and $\mathrm{SED}=0.584$ ),

Table 2 Parameter values estimated for each process in 2008 and 2009 (using data from experiments 1 and 2)

\begin{tabular}{llll}
\hline & & \multicolumn{2}{l}{ Years } \\
\cline { 3 - 4 } Distributions & Parameters & 2008 & 2009 \\
\hline Normal & $\mu$ & $30.99 \pm 0.009$ & $30.85 \pm 0.021$ \\
Normal & $\sigma$ & $3.951 \pm 0.004$ & $2.722 \pm 0.008$ \\
Log-normal & $m$ & $3.465 \pm 0.001$ & $3.500 \pm 0.008$ \\
Log-normal & $s$ & $0.634 \pm 0.003$ & $1.089 \pm 0.019$ \\
Linear & $k$ & $0.880 \pm 0.002$ & $0.913 \pm 0.007$ \\
Bernoulli & $p$ & $0.860 \pm 0.001$ & $0.873 \pm 0.001$ \\
Beta & $B 0$ & $0.335 \pm 0.001$ & $0.371 \pm 0.002$ \\
& $R^{2}$ & 0.956 & 0.924 \\
\hline
\end{tabular}

Jackknife SEs (Eqn 14) are presented, having omitted individual plants for re-estimation of parameters. Values are mean $\pm \mathrm{SE}$. 

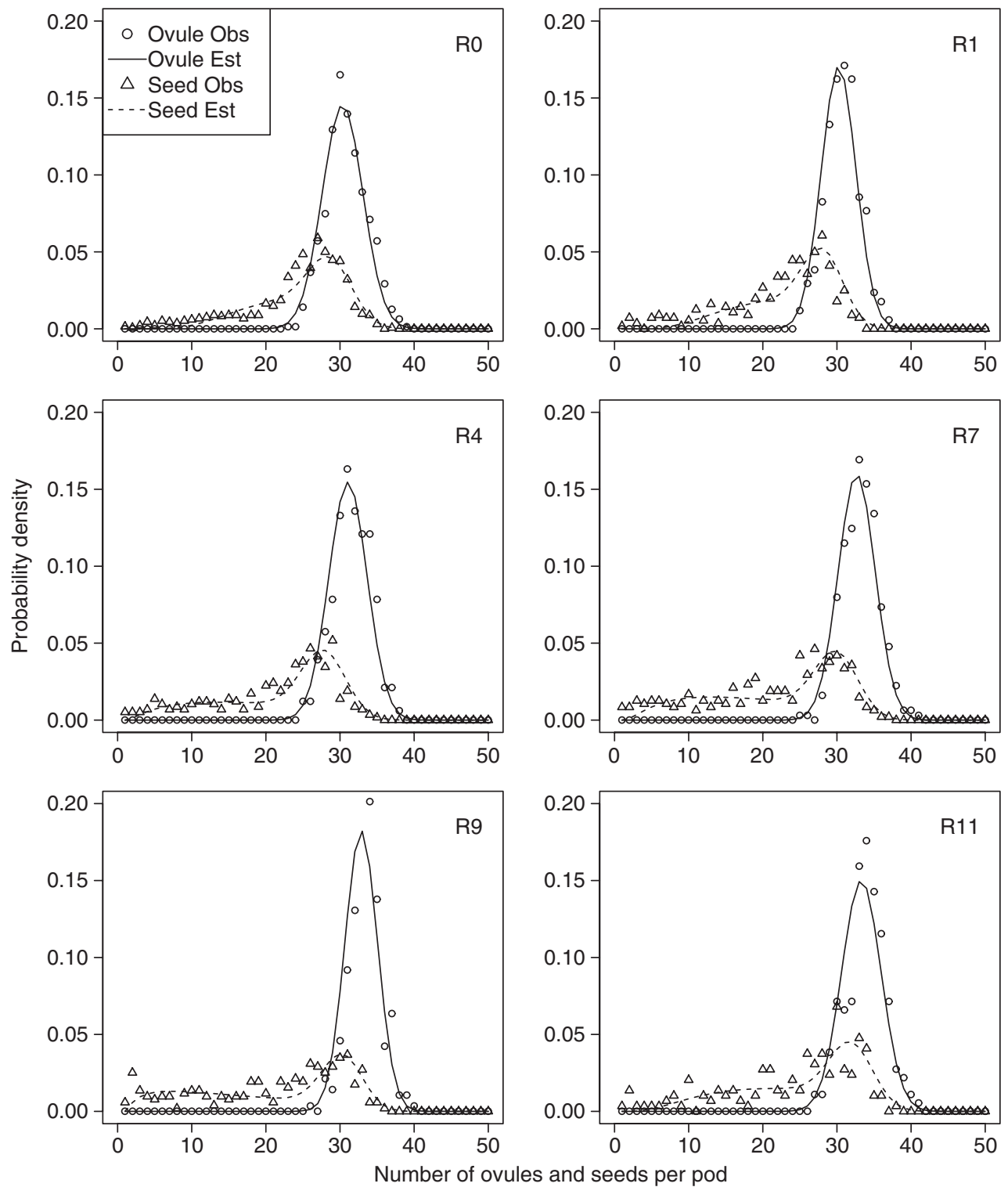

Figure 3 Estimated and observed number of ovules per flower and number of seeds per pod on the main stem R0 and for the 1st, 4th, 7th, 9th and 11th ramifications counting from the main stem apex (cv. Mendel). The symbols (Obs) and lines (Est) represent the observed and estimated values, respectively.

as given in Table 4, the means of the ramifications R0, Rl and R1 1 were larger than those of R4, R7 and R9.

\section{Effect of ramification clipping on the estimated parameter values}

The model was calibrated using the control and clipped plants (Experiment 3) to compare the effect of clipping on the values of the model parameters.

The number of ovules per ovary (Fig. 5A) and seeds per pod (Fig. 5B) varied between the control (CK) and clipped plants (R-). Clipping of all ramifications induced an increase in the number of ovules and seeds per pod on the main stem. As shown in Table 5, the mean number of ovules per pod $(\mu)$ was greater on the clipped plants. The probability of seed viability $(p)$ increased with the clipping of ramifications. The mean number of seeds per pod was larger for the clipped plants $(26.9 \pm 0.27)$ than the control plants $(24.1 \pm 0.24)$ (two-sample $t$-test, $\mathrm{SED}=0.376, t=-7.45, \mathrm{~d} f=1373, P<0.001)$.

In addition, the percentage of effective pollen grains ( $k$ ) was higher on the clipped plants than in the controls (Fig. 5C). The probability of pod survival did not differ 

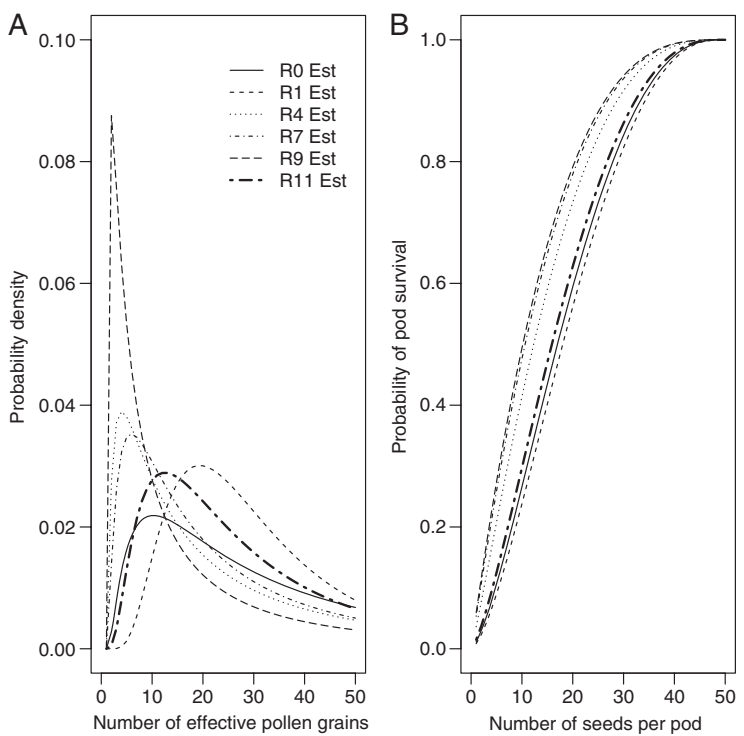

the number of pollen grains landing on a stigma $(T)$ for the simulation. We obtained the corresponding distributions of the number of ovules per ovary and the number of seeds per pod. We used the parameter values from experiment 2 from 2009 (Table 2) as an example to assess the simulation results. Comparing these to the measured results of experiment 2 (Fig. 6B), we can see that our model accurately simulated the distribution of the number of pollen grains per stigma according to the measured numbers of ovules per ovary and seeds per pod.

\section{Discussion}

The model presented in this paper simulates the processes of seed and pod formation in WOSR. The variations in the model parameters associated with the year, pod rank, inflorescence position and ramification-clipping treatment are presented. The differences in parameter values were analysed to distinguish the factors influencing seed and pod abortion. The results estimated using the model are summarised in Table 6. per flower (A) and pod survival according to the number of seeds per pod (B) on the main stem RO and for the 1st, 4th, 7th, 9th and 11 th ramifications counting from the main stem apex (cv. Mendel). 'Est' represents estimated values.

significantly between the controls and the clipped plants (Fig. 5D).

\section{Model validation}

Only the number of pollen grains per stigma was difficult to measure. On the basis of the description of a Log-Normal distribution, when the parameter $m$ is fixed, the larger the parameter $s$, the fewer of the number of pollen grains per stigma. Therefore, three pollen categories, sufficient (plenty of pollen grains, $m=3.5$, $s=1.089$, Fig. 6A), appropriate $(m=3.5, s=0.1$, Fig. $6 \mathrm{~B})$ and limited pollination $(m=3.5, s=2$, Fig. $6 \mathrm{C})$, were set up by proposing values of $m$ and $s$ in the distribution of

\section{Effect of flower/pod position on pod and seed numbers}

In WOSR, the temporal sequence of flowering and pod setting follows an acropetal pattern, with a proximal to distal progression at the individual inflorescence level. At the whole-plant level, the flowering of the inflorescences follows a basipetal pattern. The flowers located on the main stem open first, followed by the lateral inflorescences, in a top-down progression. Thus, the plant displays a centrifugal developmental sequence of flowers and pods, where the centre is the intersection between the first lateral inflorescence and the main stem, although the initiation of these structures follows the acropetal progression from the bottom to the top along the main stem.

At the whole-plant level, the numbers of pods were significantly different between inflorescences. The greatest

Table 3 Parameter values estimated for different processes in different ramifications and CV over ramifications (using data from experiment 2)

\begin{tabular}{|c|c|c|c|c|c|c|c|c|}
\hline \multirow[b]{2}{*}{ Distributions } & \multirow[b]{2}{*}{ Parameters } & \multicolumn{7}{|l|}{ Ramification no } \\
\hline & & RO & $\mathrm{R} 1$ & R4 & R7 & R9 & R11 & CV (\%) \\
\hline Normal & $\mu$ & $30.85 \pm 0.021$ & $30.73 \pm 0.017$ & $31.58 \pm 0.024$ & $33.17 \pm 0.035$ & $33.36 \pm 0.028$ & $33.79 \pm 0.079$ & 4.20 \\
\hline Normal & $\sigma$ & $2.722 \pm 0.008$ & $2.320 \pm 0.007$ & $2.561 \pm 0.010$ & $2.475 \pm 0.018$ & $2.166 \pm 0.014$ & $2.634 \pm 0.036$ & 8.33 \\
\hline Log-normal & $m$ & $3.500 \pm 0.008$ & $3.538 \pm 0.005$ & $3.471 \pm 0.012$ & $3.454 \pm 0.012$ & $3.310 \pm 0.020$ & $3.547 \pm 0.024$ & 2.48 \\
\hline Log-normal & $s$ & $1.089 \pm 0.019$ & $0.615 \pm 0.017$ & $1.363 \pm 0.022$ & $1.169 \pm 0.021$ & $1.581 \pm 0.020$ & $0.862 \pm 0.053$ & 31.0 \\
\hline Linear & $k$ & $0.913 \pm 0.007$ & $0.764 \pm 0.005$ & $0.591 \pm 0.008$ & $0.606 \pm 0.009$ & $0.252 \pm 0.004$ & $0.664 \pm 0.019$ & 28.1 \\
\hline Bernoulli & $p$ & $0.873 \pm 0.001$ & $0.869 \pm 0.002$ & $0.835 \pm 0.001$ & $0.861 \pm 0.002$ & $0.864 \pm 0.002$ & $0.906 \pm 0.004$ & 2.64 \\
\hline \multirow[t]{2}{*}{ Beta } & Bo & $0.371 \pm 0.002$ & $0.386 \pm 0.003$ & $0.290 \pm 0.003$ & $0.260 \pm 0.003$ & $0.252 \pm 0.004$ & $0.342 \pm 0.009$ & 18.2 \\
\hline & $R^{2}$ & 0.924 & 0.966 & 0.967 & 0.971 & 0.965 & 0.986 & \\
\hline
\end{tabular}

Jackknife SEs (Eqn 14) are presented, having omitted individual plants for re-estimation of parameters. Values are mean \pm SE.

R0 denotes the main stem; R1, R4, R7, R9, R11 denote the 1st, 4th, 7th, 9th and 11th ramification counting from the main stem apex, respectively. 
Table 4 Mean number of seeds per pod for the main stem R0 and ramifications R1, R4, R7, R9 and R11 (using data from Experiment 2), SED =0.584, $\mathrm{d} f=2232$

\begin{tabular}{lllllll}
\hline Inflorescences & R0 & R1 & R4 & R7 & R9 & R11 \\
\hline Mean & 24.1 & 22.4 & 21.4 & 21.6 & 21.1 & 24.4 \\
\hline
\end{tabular}

number of pods was found on the main stem, and the number of pods increased from the top to the bottom in the ramifications. Moreover, the number of ovules per pod slightly increased with inflorescence position from the top to the bottom, while the number of seeds per pod was not significantly different between the inflorescences. Within inflorescences, the number of ovules per flower remained constant, though the number of seeds per pod decreased from the base to the tip of the inflorescence (Wang et al., 2011). The model estimates are in accordance with the experimental data. The mean number of ovules per ovary $(\mu)$ did not vary with the pod rank
(Fig. 1A), though the number increased slightly on ramifications from the top (30.8) to the bottom (33.8) of the plant (Table 3). The number of seeds per pod was larger on the main stem R0 and ramifications R 1 and R11, but there was no difference between the other ramifications within a single plant (Fig. 3). The results indicate that the flower/pod position related to the developmental pattern of the plant indeed influences the number of pods or seeds.

\section{Effect of pollination limitation}

One of the important contributions of our model is the finding that the distribution of the number of pollen grains deposited on a stigma can be simulated using a Log-Normal distribution with the parameters $m$ and $s$. The distribution of the number of pollen grains per stigma $m$ remained constant, but the parameter $s$ varied within or between inflorescences, although no tendency could be found. According to the findings of Mesquida et al. (1988),
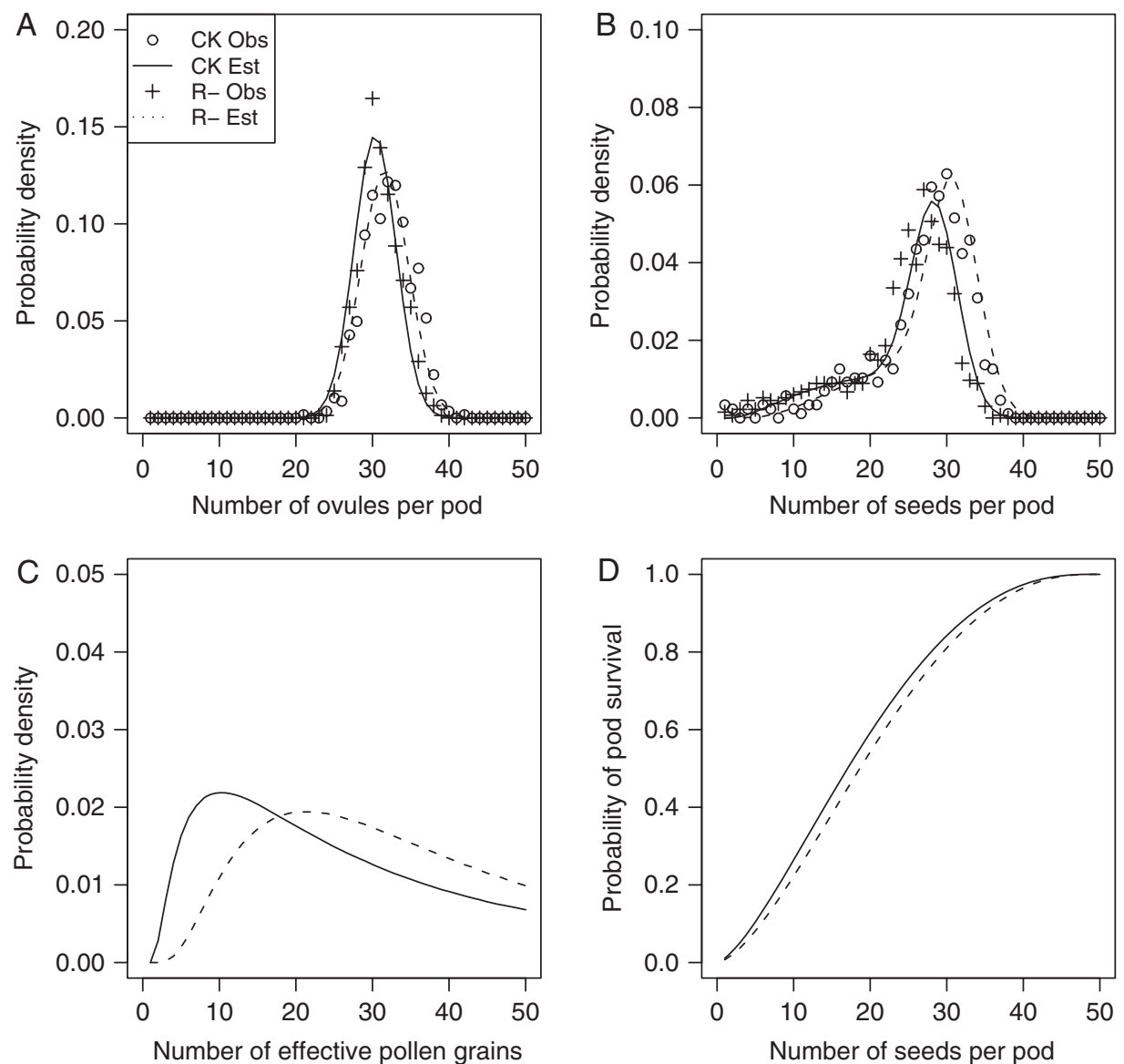

Figure 5 Estimated distributions for each process. (A) Number of ovules per flower, (B) number of seeds per pod, (C) number of pollen grains per flower and (D) probability of pod survival according to the number of seeds per pod on the main stem in the controls and the clipped plants (cv. Mendel). The symbols (Obs) and lines (Est) represent the observed and estimated values, respectively. 
Table 5 Parameter values estimated for each process in the clipped (R-) and control (CK) plants (using data from experiment 3)

\begin{tabular}{llll}
\hline & & \multicolumn{2}{l}{ Treatments } \\
\cline { 3 - 4 } Distributions & Parameters & CK & R- \\
\hline Normal & $\mu$ & $30.85 \pm 0.021$ & $32.12 \pm 0.070$ \\
Normal & $\sigma$ & $2.722 \pm 0.008$ & $3.110 \pm 0.018$ \\
Log-normal & $m$ & $3.500 \pm 0.008$ & $3.569 \pm 0.007$ \\
Log-normal & $S$ & $1.089 \pm 0.019$ & $0.752 \pm 0.014$ \\
Linear & $k$ & $0.913 \pm 0.007$ & $0.990 \pm 0.008$ \\
Bernoulli & $p$ & $0.873 \pm 0.001$ & $0.917 \pm 0.001$ \\
Beta & $B 0$ & $0.371 \pm 0.002$ & $0.393 \pm 0.002$ \\
& $R^{2}$ & 0.924 & 0.962 \\
\hline
\end{tabular}

Jackknife SEs (Eqn 14) are presented, having omitted individual plants for re-estimation of parameters. Values are mean $\pm \mathrm{SE}$.

who evaluated the distribution of pollen grains in oilseed rape, most flowers receive a sufficient number of pollen grains to fertilise the ovules. Furthermore, the pollination time between the distal pods on the main stem and the basal pods of the ramifications was synchronous, indicating that the decrease in the number of seeds per pod observed on the main stem was not due to a decrease in the number of pollen grains. This finding may be related to pollen germination, which is described as the proportion of effective pollen grains per stigma $(k)$ in our model. This parameter first increased and then decreased with the pod rank (Fig. 1B) and for ramifications positioned from the top to the bottom of the plant (Table 3). We can therefore conclude that the decrease in the number of seeds per pod at the end of the inflorescence could be due to a decline in pollen germination, rather than a lack of pollen grains deposited on the stigma.

\section{Effect of resource competition}

WOSR plants are quite plastic, showing compensation among different yield components (Jullien et al., 2011; Thurling, 1974). The vegetative and reproductive growth stages of WOSR plants occur simultaneously during the flowering stage. This includes the growth of the leaves, stems and ramifications and the differentiation of flower buds, which require large amounts of nutrients and water. The contents of assimilates are regulated at the level of the individual flower or fruit as well as associated with the development of ovaries and the maturation of fruit. At each stage, the initiation or expansion of an organ requires available resources above a certain threshold (Ganeshaiah et al., 1986).

In our model, ramification clipping led to an increase in the mean number of ovules per ovary $(\mu)$ on the main stem (Table 5). Additionally, the probability of a fertilised ovule developing into a seed $(p)$ increased slightly, which
A

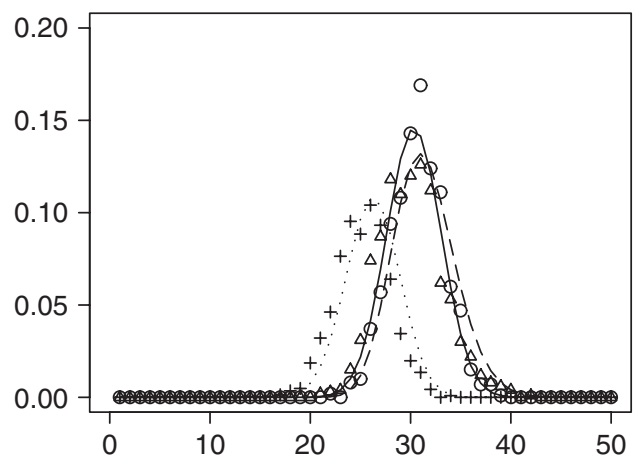

\section{B}

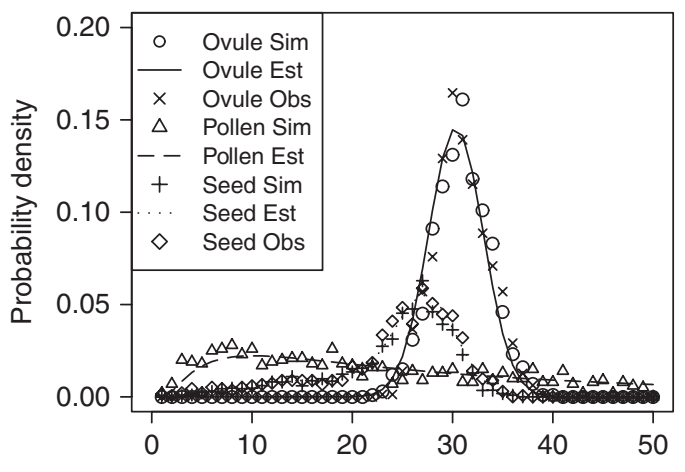

C

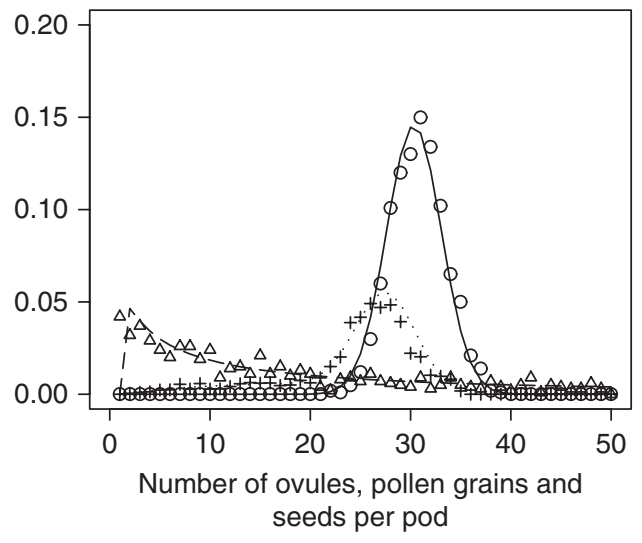

Figure 6 Monte-Carlo simulation and calculation of the number of ovules per flower, the estimated distribution of the number of pollen grains per flower and number of seeds per pod using different parameter values. The three pollen categories are sufficient (A), appropriate (B) and limited (C) pollination. The symbols (Sim) and lines (Est) represent the simulated and estimated values, respectively.

is consistent with our previous experimental findings. The mean number of seeds per pod increased at the tip of the stems of plants following ramification clipping (Wang et al., 2011). In a previous study, Tayo \& Morgan (1979) analysed the impact of shading and leaf removal on the number of pods on the main stem. These authors found that both treatments resulted in a reduced pod number in oilseed rape. Pechan \& Morgan (1985) indicated that defoliation of the terminal inflorescence at anthesis 
Table 6 Variations in the parameters estimated for each process in different factors

\begin{tabular}{llllll}
\hline Distribution & Parameter & Year $^{\mathrm{a}}$ & Pod rank $^{\mathrm{b}}$ & Ramification $^{\mathrm{c}}$ & Treatment $^{\mathrm{N}}$ \\
\hline Normal & $\mu$ & Constant & Constant & Increase & Increase \\
Log-normal & $s$ & Vary & Vary & Vary & Constant \\
Linear & $k$ & Vary & Decrease & Vary & Increase \\
Bernoulli & $p$ & Constant & Constant & Constant & Increase \\
Beta & $B 0$ & Vary & Vary & Vary & Constant \\
\hline
\end{tabular}

ayear (2008 and 2009)

b Pod rank on the main stem.

cInflorescence position (R0, R1, R4, R7, R9 and R11 from the top to the bottom).

${ }^{\mathrm{d} C l i p p i n g-r a m i f i c a t i o n ~ t r e a t m e n t ~(a l l ~ r a m i f i c a t i o n s ~ a r e ~ r e m o v e d) . ~}$

causes a significant reduction in the weight of pods per plant as a result of a reduction in the weight of individual pods. These results indicate that the competition for assimilates affects pod and seed production.

This resource competition hypothesis is further supported by the fact that the number of seeds per pod decreases from the base to the tip of the inflorescence (Wang et al., 2011), although the ovule number per flower does not vary with position. As the proximal pods develop earlier and tend to sequester assimilates, to the detriment of more distal pods, it may be speculated that the decrease in seed numbers per pod results from a limitation of assimilate availability. In many species, staminate flower production varies with resource availability, with these flowers developing predominately at distal positions within an inflorescence (Diggle \& Miller, 2013 and references therein). In Solanum, fruit removal reduces the proportion of staminate flowers (Diggle \& Miller, 2013). The results also provide further confirmation of this phenomenon. Similar to the production of staminate flowers, the abortion of flowers or young seeds predominately located on the distal side of an inflorescence may maximise reproductive output by precluding the investment of limited resources in seeds that will not be able to reach maturity (Miller \& Diggle, 2007).

\section{Model validation}

The model can simulate the number of ovules per ovary, the number of pollen grains per stigma and the number of seeds per pod. The simulation accuracy was satisfactory although could still be improved. To better understand the process of seed production, parameter sensitivity analysis needs to be applied to analyse which parameter is more important, especially for the number of pollen grains per stigma, as the verification of the distribution of this parameter based on experimental data was difficult. Resampling methods (bootstrapping and jackknifing) have been applied to estimate the variability of the parameters by using random subsets. The results of the two methods indicated that the parameters were quite stable (Wang, 2011). To improve the estimation further, another estimation method could be tried, as the parameters cannot be simultaneously estimated using GLSQR.

Furthermore, the model was used to simulate the distribution of the number of ovules and seeds per pod for four WOSR cultivars. The results indicate that the number of ovules per ovary and seeds per pod are closely related to genetic factors. The parameter values differ between cultivars (Wang et al., 2010). Thus, the model can be used for different cultivars, even with different oilseed species having a similar growth pattern. The model described herein appears to be a satisfactory tool for analysing the variations in seeds and pods within a plant. Further investigation of the pollination process in WOSR is necessary to refine this model. As a second step, a new study should be done to optimise the calibration of the parameters.

In conclusion, our model allows us to reproduce the processes of seed and pod formation in WOSR based on a limited number of parameters. These model parameters are useful as selection criteria and can be employed to study variability in seed production and to estimate the contributions of genetic and environmental factors to seed abortion, given a relevant experimental design. As seed development plays an important role in determining seed yields, our model can be combined with a model of plant growth at the organ level, such as the Functional-Structural plant model Greenlab (Jullien et al., 2011), to refine the simulation of plant growth in cultivars by computing source-sink parameters for plant organs and would help breeders to shorten the breeding period.

\section{Acknowledgements}

We thank the people from INRA EGC involved for their kind assistance on experiments. This work was supported by China 863 Program (\#2012AA101906-2), and NSFC (\#31170670) and partly supported by China Scholarship Council (CSC), which provides the PhD scholarship of Xiujuan Wang.

\section{References}

Akaike H. (1973) Information theory and an extension of maximum likelihood principle. In Second International Symposium on Information Theory, pp. 267-281. Eds B.N. Petrov and F. Csaki. Budapest: Akademiai Kiado.

Arathi H.S., Ganeshaiah K.N., Shaanker R.U., Hegde S.G. (1999) Seed abortion in Pongamia pinnata (Fabaceae). American Journal of Botany, 86, 659-662. 
Ashman T.L., Hitchens M.S. (2000) Dissecting the causes of variation in intra-inflorescence allocation in a sexually polymorphic species, Fragaria virginiana (Rosaceae). American Journal of Botany, 87, 197-204.

Bertin R.I. (1982) Floral biology, humming bird pollination and fruit production of trumpet creeper (Campsis radicans, Bignoniaceae). American Journal of Botany, 69, 122-134.

Boselli M., Volpe B., Divaio C. (1995) Effect of seed number per berry on mineral composition of grapevine (Vitis vinifera L.) berries. The Journal of Horticultural Science, 70, 509-515.

Brookfield P.B., Ferguson L.B., Watkins C.B., Bowen J.H. (1996) Seed number and calcium concentrations of Braeburn' apple fruit. The Journal of Horticultural Science, 71, 265-271.

Brunet J., Charlesworth D. (1995) Floral sex allocation in sequentially blooming plants. Evolution, 49, 70-79.

Burd M. (1994) Bateman's principle and plant reproduction: the role of pollen limitation in fruit and seed set. Botanical Review, 60, 83-139.

Cournède P.H., Letort V., Mathieu A., Kang M.Z., Lemaire S., Trevezas S., Houllier F., de Reffye P. (2011) Some parameter estimation issues in functional-structural plant modelling. Math Model Natural Phenomenon, 6, 133-159.

De Reffye P., Parvais J., Mossu G., Lucas P. (1978) Influence des aléas de la pollinisation sur les rendements du cacaoyer modèle mathématique et simulation. Café Cacao Thé, 22, 251-274.

Diepenbrock W. (2000) Yield analysis of winter oilseed rape (Brassica napus L.): a review. Field Crops Research, 67, 35-49.

Diggle P.K. (1995) Architectural effects and the interpretation of patterns of fruit and seed development. Annual Review of Ecological and Evolutionary Systems, 26, 531-552.

Diggle P.K., Miller J.S. (2013) Developmental plasticity, genetic assimilation, and the evolutionary diversification of sexual expression in Solanum. American Journal of Botany, 100, 1050-1060.

Falque M., Vincent A., Vaissiere B., Eskes A. (1995) Effect of pollination intensity on fruit and seed set in cacao (Theobroma cacao L.). Sexual Plant Reproduction, 8, 354-360.

Ganeshaiah K.N., Shaanker R.U., Shivashankar G. (1986) Stigmatic inhibition of pollen grain germination-its implication for frequency distribution of seed number in pods of Leucaena leucocephala (Lam) de Wit. Oecologia (Berlin), 70, 568-572.

Guitian J., Navarro L. (1996) Allocation of reproductive resources within inflorescences of Petrocoptis grandiflora (Caryophyllaceae). Canadian Journal of Botany, 74, $1482-1486$.

Guo Y., Ma Y., Zhan Z., Li B., Dingkuhn M., Luquet D., De Reffye P. (2006) Parameter optimization and field validation of the functional-structural model GREENLAB for Maize. Annals of Botany, 97, 217-230.

Hiei K., Ohara M. (2002) Variation in fruit- and seed set among and within inflorescences of Melampyrum roseum var. japonicum (Scrophulariaceae). Plant Species Biology, 17, $13-23$.

Johnstone A. (2000) Reproduction in flowering plants. In Biology: Facts $\theta$ Practice for A Level, pp. 94-95. Oxford, UK: Oxford University Press.

Jullien A., Mathieu A., Allirand J.-M., Pinet A., de Reffye P., Cournède P.H., Ney B. (2011) Characterization of the interactions between architecture and source-sink relationships in winter oilseed rape (Brassica napus) using the GreenLab model. Annals of Botany (London), 107, $765-779$.

Lee T.D. (1980) Extrinsic and Intrinsic Factors Controlling Reproduction in an Annual Plant. Urbana-Champaign, IL: University of Illinois at Urbana-Champaign.

Lee T.D. (1988) Patterns of fruit and seed production. In Plant Reproductive Ecology: Patterns and Strategies, pp. 179-202. Eds J.D. Lovett and D.L. Lovett. New York, NY: Oxford University Press.

Lescourret F., Blecher N., Habib R., Chadoeuf J., Agostini D., Pailly O., Vaissière B., Poggi I. (1999) Development of a simulation model for studying kiwi fruit orchard management. Agricultural Systems, 59, 215-239.

May P., Antcliff A. (1963) The effect of shading on fruitfulness and yield in the sultana. Journal of Horticultural Science, $\mathbf{3 8}$, $85-94$.

Mendham N.J., Shipway P.A., Scott R.K. (1981) The effects of delayed sowing and weather on growth, development and yield of winter oil-seed rape (Brassica napus). Journal of Agricultural Science, 96, 389-416.

Mesquida J., Renard M., Pierre J.S. (1988) Rapeseed (Brassica napus L.) productivity: the effect of honeybees (Apis mellifera L.) and different pollination conditions in cage and field tests. Apidologie, 19, 51-72.

Miller J.S., Diggle P.K. (2007) Correlated evolution of fruit size and sexual expression in andromonoecious Solanum sections Acanthophora and Lasiocarpa (Solanaceae). American Journal of Botany, 94, 1706-1715.

Mossu G., Paulin D., De Reffye P. (1981) Influence de la floraison et de la pollinisation sur les rendements du cacaoyer. Liaisons mathématiques entre les données expérimentales. Equation du rendement. Café Cacao Thé, 25, 155-168.

Nakamura R.R. (1986) Maternal investment and fruit abortion in Phaseolus vulgaris. American Journal of Botany, 73, 1049-1057.

Obeso J.R. (1993) Does defoliation affect reproductive output in herbaceous perennials and woody plants in different ways? Functional Ecology, 7, 150-155.

Parvais J.P., De Reffye P., Lucas P. (1977) Observations sur la pollinisation libre chez Theobroma cacao : analyse mathématique des données et modélisation. Café Cacao Thé, 21, 253-262.

Pechan P.M. (1988) Ovule fertilization and seed number per pod determination in oilseed rape. Annals of Botany, 61, 201-207. 
Pechan P.A., Morgan D.G. (1985) Defoliation and its Effects on Pod and Seed Development in Oil Seed Rape (Brassica napus L.). Journal of Experimental Botany, 36, 458-468.

Pyke N.B., Alspach P.A. (1986) Inter-relationship of fruit weight, seed number and seed weight in kiwifruit. Journal of Agricultural Science, 20, 153-156.

de Reffye P. (1974) Le contôle de la fructification et de ses anomalies chez les Coffea arabica, robusta et leurs hybrides "Arabusta". Café Cacao Thé, 18, 237-254.

Sahinler S., Topuz D. (2007) Bootstrap and Jackknife resampling algorithms for estimation of regression parameters. Journal of Applied Quantitative Methods, 2, 188-199.

Solomon B.P. (1988) Patterns of pre- and postfertilization resource allocation within an inflorescence: evidence for interovary competition. American Journal of Botany, 75, 1074-1079.

Stephenson A.G. (1980) Fruit set, herbivory, fruit reduction and fruiting strategy of Catalpa speciosa (Bignoniaceae). Ecology, 61, 57-64.

Stephenson A.G. (1981) Flower and fruit abortion: proximate causes and ultimate functions. Annual Review of Ecological Systems, 12, 253-279.

Takahata Y., Konno N., Hinata K. (2008) Genotypic variation for floral characters in Brassica and allied genera with special reference to breeding system. Breeding in Science, 58, 385-392.

Tayo T.O., Morgan D.G. (1979) Factors influencing flower and pod development in oil-seed rape (Brassica napus L.). Journal of Agricultural Science, 92, 363-373.

Thomson J.D. (1989) Deployment of ovules and pollen among flowers within inflorescences. Evolutionary Trends in Plants, 3, 65-68.

Thurling N. (1974) Morphophysiological determinants of yield in rapeseed (Brassica campestris and Brassica napus). II.* Yield components. Australian Journal of Agricultural Research, 25, 711-721.
Tittonel E. D. (1990) Evènements liés à l' évolution florale chez le colza Brassica napus L. var Oleifera Metzg. PhD thesis, Université Paris 6, Paris, France.

Udovic D., Aker C. (1981) Fruit abortion and the regulation of fruit number in Yucca whipplei. Oecologia, 49, 245-248.

Wang X.J. (2011) A probabilistic model of flower fertility and factors influencing seed production in winter oilseed rape (Brassica napus L.). PhD Thesis, Ecole Centrale de Paris, France.

Wang X.J., Mathieu A., Cournède P.H., Allirand J.M., Jullien A., de Reffye P., Zhang B.G. (2009) Stochastic models in floral biology and application to the study of oilseed rape fertility. In International Symposium on Plant Growth Modeling, Simulation, Visualization and Applications (PMA09), 9-12 November 2009, pp. 175-182. Eds B.-G. Li, M. Jaeger and Y. Guo. Beijing, China: IEEE Computer Society.

Wang X.J., Mathieu A., Cournède P.-H., Allirand J.-M., Jullien A., de Reffye P., Zhang B.G. (2010) Calibration of a probabilistic model of oilseed rape fertility to analyze the inter-cultivar variability in number of seeds. In 6th International Workshop on Functional-Structural Plant Models, 12-17 September 2010, University of California, Davis.

Wang X.J., Mathieu A., Cournède P.-H., Allirand J.-M., Jullien A., de Reffye P., Zhang B.G. (2011) Variability and regulation of the number of ovules, seeds and pods according to assimilate availability in winter oilseed rape (Brassica napus L.). Field Crops Research, 122, 60-69.

Wertheim S.J. (1991) Malus cv. Baskatong as an indicator of pollen spread in intensive apple orchards. Journal of Horticultural Science, 66, 635-642.

Yin X., Goudriaan J.A.N., Lantinga E.A., Vos J.A.N., Spiertz H.J. (2003) A flexible sigmoid function of determinate growth. Annals of Botany, 91, 361-371. 